\title{
Diseño desde el ser humano. Richard Neutra y su proyecto para América Latina.
}

\author{
Design for human beings. Richard Neutra and his project for Latin America.
}

Recibido: mayo/2018

Aceptado: agosto/2018

Dra. Catherine Ettinger ${ }^{1}$

El diseño de estructuras, si nos alejamos
de "lo abstracto" concierne, sobre todo,
labor para y con seres humanos.

(Neutra, 1954: v)

\section{Resumen}

Richard J. Neutra (1892-1970), arquitecto austriaco emigrado a California en la década de 1920, ha sido caracterizado en la historiografía del movimiento moderno como un gran técnico que depuró los lenguajes modernos en residencias para su clientela del sur de California. Esta versión sobre Neutra opaca contribuciones teóricas relevantes que se vinculan, por lo menos parcialmente, con sus experiencias en América Latina y su trabajo en Puerto Rico, en donde desarrolló diseños para escuelas, clínicas, centros comunitarios y hospitales, además de reflexionar sobre el tema de vivienda. Este trabajo rescata de textos éditos como Arquitetura social em paises de clima quente e inéditos como manuscritos y discursos que dio en distintos países de América Latina el pensamiento de Neutra sobre el diseño en relación con el ser humano como cuerpo y como ser social. Se muestra como, a partir de sus lecturas de neurociencias y la reflexión que hizo en relación con las soluciones que había ideado para Puerto Rico entre 1943 y 1945, elaboró fundamentos teóricos humanistas.

\section{Palabras Clave:}

Richard Neutra; Biorealismo; Arquitectura latinoamericana; Puerto Rico.

\begin{abstract}
Richard J. Neutra (1892-1970), Austrian architect who emigrated to California in the 1920s, has been characterized in the historiography of the Modern Movement as a technical architect who purified modern languages in residences for his Southern California clientele. This version of Neutra hid from view his relevant theoretical contributions that are related -at least partially- to his experiences in Latin America and his work in Puerto Rico where he developed designs for schools, clinics, community centers and hospitals and reflected on collective housing. This article -based on a revision of published texts such as Architecture of Social Concern for Regions of Mild Climate as well as unpublished manuscripts and speeches given in Latin America- Neutra's thought on the relationship between design and humans, both as biological and social beings. It shows how, based on his readings in Neuroscience and his reflections on the solutions he had developed for Puerto Rico between 1943 and 1945 he constructed humanistic theoretical foundations.
\end{abstract}

\section{Keywords:}

Richard Neutra; Biological realism; Latin American architecture; Puerto Rico.

\footnotetext{
${ }^{1}$ Profesor-Investigador Titular "C" de Tiempo Completo Universidad Michoacana de San Nicolás Hidalgo. Facultad de Arquitectura. SNI Nivel II . Mail: crettingerm@gmail.com
} 


\section{Introducción.}

La imagen de Richard Neutra (1892-1970) está irrevocablemente ligada a sus casas californianas. La fotografía de Julius Schulman de la casa Kaufmann al atardecer, con los cerros del desierto en tonos de gris de fondo y la mujer acostada en un tumbón frente a la alberca, es probablemente una de las imágenes más reconocidas de su trabajo. Esta fotografía, y otras que difundieron las casas realizadas para su clientela adinerada del sur de California, es elocuente en relación con el esmerado tratamiento técnico de sus obras, el papel central que ocupó el sitio en sus diseños y la claridad formal que ostentó en el uso de lenguajes modernos; lo que no logra comunicar es el profundo interés de Neutra por el ser humano y su comodidad como asunto medular en el diseño arquitectónico.

Neutra fue, además de profuso diseñador, profuso escritor. Dejó numerosos textos que, aunque en ocasiones sean de difícil lectura, dan evidencia de los fundamentos teóricos de su trabajo y de la honda reflexión sobre la esencia del quehacer del arquitecto: el ser humano. Los escritos muestran otro Neutra, un visionario con inquietudes alejadas de la imagen de una arquitectura glamurosa. En ellos se reflexiona sobre temas que se tornarían de interés medio siglo después como el diseño ambiental o la percepción de la arquitectura. Dan fe además de su gran preocupación por el sur, por el trópico y por sus habitantes pobres. Como buen moderno, creía en la capacidad de la arquitectura de forjar cambios en los individuos y también en las colectividades; en su poder de transformación social. Pregonaba un diseño centrado en el ser humano, atento a las condiciones naturales del sitio y sensible a las necesidades sociales.

En este sentido, la historiografía de la arquitectura no le ha hecho justicia a Neutra, caracterizándolo como un técnico (Benevolo, 1977:641) dedicado a la arquitectura residencial en California (Hitchcock, 1993:117; Giedion, 1967:500). Las omisiones historiográficas han dado como resultado un renovado interés en Neutra con atención a sus inquietudes en relación con el sitio (Leatherbarrow, 2000), el psicoanálisis (Lavin, 2005), la neurociencia (Mallgrave, 2011), los países del sur (Tippey, 2016) y el paisaje (Treib, 2017). Lavin (2005:14) hace el llamado para considerar a Neutra una figura principal de la modernidad, aduciendo la impor- tancia de su producción teórica, que poco ha figurado en revisiones historiográficas.

En relación con América Latina Neutra es un tema candente. Sus proyectos para Puerto Rico, las giras que realizó en los años 40 y 50 y la constante publicación de sus obras en revistas de gremio en los países de la región le han conferido un papel importante. Para el caso de México, se ha señalado su influencia en la arquitectura residencial de los años cincuenta, particularmente en el fraccionamiento del Pedregal de San Ángel (Rovira y Rueda, 2014; Rueda, 2009; Santa Ana, 2014). La presencia constante de Neutra en la prensa gremial y la consecuente influencia se examinó también para el caso de Brazil (Critelli de Campos, 2015; Fraser, 2000; Segawa, 1998:149.) Lira (2010) ha señalado el interés de Neutra por el tema de la planificación en la región. Estos trabajos en conjunto reconocen la importancia de Neutra en América Latina donde sus publicaciones y su presencia dejaron aportaciones a la arquitectura local.

El presente trabajo se suma al corpus existente sobre Neutra ahondando en su pensamiento en relación con el ser humano. A través de la revisión de sus discursos, textos inéditos y publicaciones -privilegiando aquellas realizadas en América Latina-, se identifica dos distintas maneras de concebir al ser humano en relación con la arquitectura. La primera como ser social con atributos culturales y la segunda como ser corpórea. Ambas concepciones marcaron sus propuestas para la región.

Este acercamiento invita a revisar las versiones más difundidas sobre Neutra en la historiografía de la arquitectura en varios sentidos. Por una parte se tiene que enriquecer el potente imaginario forjado de su arquitectura doméstica a través de la serie Arts \& Architecture y su programa de Case Study Houses, para prestar atención a la arquitectura social, en particular la escolar, la hospitalaria y la vivienda colectiva. Por otra, se espera complementar la historiografía que enfatizó la calidad técnica de su obra, al reconocer su perspectiva desde el ser humano en relación con la percepción sensorial. Por último, se espera contribuir a una revaloración de la importancia de Neutra para los arquitectos latinoamericanos, frente a la historiografía que al observar la influencia de Le Corbusier, particularmente en Brasil, ha opacado la relevancia de otras figuras en la región. 


\section{Neutra, la modernidad arquitec- tónica y el ser humano.}

Resulta una obviedad que el ser humano está al centro del diseño arquitectónico, pero hay maneras muy distintas de imaginar ese ser. Probablemente la formulación más contundente y diseminado del siglo $\mathrm{XX}$ sobre la relación entre ser humano y espacio arquitectónico resulta de la analogía entre máquina y espacio. La descripción corbusiana de la casa como "máquina para habitar" remite a la idea del diseño mínimo y eficiente basado en un habitante estándar. En este paradigma, el estudio del usuario privilegiaba las medidas sobre otros aspectos como pudiera ser la cultura, los usos y costumbres, y presagiaba el desarrollo de El Modulor publicado en 1950. Aunque desde luego que el pensamiento de Le Corbusier, en relación con la vivienda, tenía mayor complejidad, la analogía con la máquina fue tan potente que opacó otras formulaciones y predominó esta posición maquinista y universal.

Al igual que la modernidad no fue unívoca aunque algunas versiones la caracterizan así-la manera de imaginar al ser que ocuparía el espacio arquitectónico tampoco lo fue. Iñaki Ábalos (2000: 20-25) ha indagado la idea del hombre abstraído, el hombre nietzcheano en los proyectos de casas-patio de Mies van der Rohe, donde el ser humano es un moderno, aislado, solo. El ser humano que recorre el espacio se asomó en el trabajo de Eileen Gray con la propuesta de diseño a partir de trazar los movimientos de los diferentes usuarios privilegiando los usos y las acciones sobre la función (Espegel, 2007: 114). En su Casa E1027 en Cap St. Martín el ejercicio de dibujar los trayectos del personal de servicio y de los habitantes de la casa fue determinante en el diseño. No se quiere sugerir que fuera la única consideración, pero la idea del ser en movimiento y de una concepción de las distintas funciones de las personas que habitaban el espacio se usó para lograr una eficiencia distinta a la de los espacios mínimos de Le Corbusier.

Richard Neutra, en sus escritos, mostró diversas posiciones con respecto al ser humano, con una relevante distinción entre el cliente y el usuario final. Sus ideas al respecto se derivan de varias experiencias e intereses, incluyendo su cercanía a la familia de Sigmund Freud en su juventud y sus lecturas sobre psicoterapia (Lavin, 2005), su interés en las neurociencias (Mallgrave,2011), y una larga hospitalización de joven cuando, después de contraer malaria y tuberculosis durante su servicio militar, fue obligado a pasar un año y medio en un sanatorio suizo. Esta experiencia lo sensibilizó a la perspectiva no solo del paciente hospitalario, sino en general a la percepción de la arquitectura por parte de sus usuarios. Su contacto con Philip Lovell durante el proceso de diseño de la Casa de Reposo Lovell reforzó sus convicciones al respecto del rol que jugaba la arquitectura en el bienestar de sus usuarios y el desarrollo de su filosofía de biorealismo.

Lovell y su esposa Leah, abogaban por una vida sana a través del vegetarianismo y el ejercicio, ideas que difundieron a través de una columna en el Los Angeles Times. Neutra buscó en el diseño de la Lovell Health House en 1929 -además de la novedad muy difundida de la estructura de acero- una armonía que fomentara el bienestar físico y emocional de sus habitantes. Jugando con distintos niveles, con grandes volados y balcones suspendidos, creó una serie de espacios interiores diseñados para lograr el bienestar integral de sus habitantes -en lo psicológico, lo físico y lo espiritual. Se considera que este acercamiento a los Lovell fue clave en el desarrollo de sus ideas sobre biorealismo, una filosofía que a grandes rasgos postulaba el "impacto benéfico de un ambiente bien diseñado sobre la salud general del sistema nervioso humano" (Frampton 1980:248). Recordando esta experiencia escribió "Había empezado a creer que la medicina era mejor cuando estaba versada en prevención y que la planificación urbana y el diseño edilicio podrían conformar el paquete más prometedor de medicina preventiva y un factor de fuerte influencia en impulsar la química interior de bienestar" (Neutra, [1962] 2009: 222). Este deseo de proveer a los espacios con el poder de originar bienestar lo llevó a incluir áreas para dormir en el exterior, patios privados para tomar el sol al desnudo y una cocina adecuada para la preparación de una dieta rica en vegetales. La modulación de la luz y la relación establecida entre los espacios interiores y exteriores abonaron a la creación de un ambiente armonioso.

Estas experiencias se vinculan con las concepciones del ser humano que aparecen en el discurso de Neutra sobre y para América Latina. En el, aparece un ser cultural -ya sea latino o indígenaque tiene una forma de vida que puede entrar en choque con un nuevo modelo de arquitectura mo- 
derna o bien ofrecer oportunidades de continuidad. Por otra parte, y particularmente relacionado con el tema de clima, está el ser humano corpóreo que percibe la arquitectura a través de sus sentidos. Ambas formulaciones marcaron su perspectiva sobre la región, así como sus propuestas para arquitecturas adecuadas a ella.

\section{Neutra y América Latina.}

Richard Neutra estableció una relación profunda con América Latina a través de numerosos viajes, el contacto con colegas y la realización de proyectos en la región. Aunque había viajado a México de vacaciones con anterioridad, su primer viaje profesional a la región se realizó en 1937 cuando de visitó México para impartir una conferencia en el Palacio de Bellas Artes en la ciudad de México. ${ }^{2}$ Aprovechó la oportunidad para recorrer el país y establecer contacto con figuras tan relevantes en el ámbito artístico y cultural como Diego Rivera, Frida Kahlo, Juan O'Gorman y Carlos Obregón Santacilia (Hines 1982: 189). En su diario registró su sorpresa ante los contrastes: la presencia prehispánica y los conjuntos de vivienda multifamiliar, la historia milenaria y la metrópoli, el carácter indígena y occidental y, "el inmenso Rivera" y su "diminuta muñeca de pelo negro" (citado por Hines, 1982:189).

Este viaje le sirvió de introducción a América Latina, región en la cual desarrollaría uno los proyectos más significativos de su amplia carrera: el diseño de escuelas, clínicas, hospitales y centros comunitarios en Puerto Rico entre 1943 y 1945 (Hines, 1982: 195). Viajó a la isla a instancias del Departamento del Estado de Estados Unidos y a invitación del gobernador Rexford Tugwell para participar en el diseño de escuelas, hospitales y centros comunitarios, tanto rurales como urbanos. Neutra fungió como coordinador de un equipo local; los diseños realizados -aunque la mayoría no fueron construidos como tal- recibieron mucha difusión a través de diversas publicaciones. En ellos, Neutra pudo seguir explorando las posibilidades de diseño en clima templado -que venía realizando en California- pero ahora con condiciones climáticas más extremas y con fuertes limitaciones de costo (Architectural Forum, 1945: 126-130). Aprovechando la cercanía, en marzo 1945 viajó a Santo Domingo, República Dominicana ${ }^{3}$ y a La Habana Cuba, ${ }^{4}$ donde se reunió con colegas e impartió conferencias.

Auspiciado de nuevo por el Departamento de Estado de los Estados Unidos, Neutra realizó una gira de buena voluntad a Sur América en noviembre de 1945 en el marco de la política de "Buenos Vecinos" que había implementado Franklin D. Roosevelt ante la amenaza de influencias comunistas en la región. En esa ocasión visitó Ecuador (Guayaquil), Perú (Lima, Arequipa, Cuzco), Bolivia (La Paz), Argentina (Buenos Aires), Uruguay (Montevideo) y Brasil ${ }^{5}$ (São Paulo, Rio de Janeiro, Minas Gerais, y Rui Grande do Sul). Por lo general, sus conferencias fueron precedidas por visitas a las obras recientes o en proceso de construcción con la finalidad de que diera asesoría donde fuera posible. Aprovechó las visitas para incorporar en sus discursos alusiones a la situación local. ${ }^{6}$

Para concluir el reporte y resumir la gira, Neutra escribió:

"Creo que aparte de las reuniones sociales de costumbre, útiles para fomentar la buena voluntad, mi procedimiento de hacer que los problemas de la ciudad visitada fueran el tema de las conferencias formales, mesas redondas y transmisiones resultó satisfactorio y fue bien recibido. Evidentemente requirió de un acopio veloz de información, pero rindió, según mis amigos locales, la publicidad verdaderamente constructiva y el agradecimiento de esfuerzo de cooperación cultural del Departamento de Estado."7

\footnotetext{
${ }^{2}$ El evento se realizó bajo el auspicio de la Secretaría de Educación Pública con la participación de la Liga de Escritores y Artistas Revolucionarios, la Sociedad de Arquitectos Mexicanos y la Escuela Superior de Construcción.

Archivo Neutra (Richard and Dion Neutra Papers, Colección 1179, Charles E. Young Research Library, UCLA), caja 1419, expediente 29.

3 [Nota periodística. Diario de la Nación, Ciudad Trujillo, República Dominicana, 7 marzo 1945]. Archivo Neutra, caja 1419, expediente 1410.

4 [Nota periodística. Diario de la Marina, La Habana, 15 marzo 1945]. Archivo Neutra, caja 1419, expediente 29.

${ }^{5}$ Notas sobre la presencia de Neutra en Brasil aparecieron en O Globo (17 novembro de 1945), Diario da Noite de Sao Paolo (19 novembro de 1945) y O Jornal de Rio de Janeiro (20 noviembre de 1945). Archivo Neutra, caja 1419, expediente 29.

${ }^{6}$ [Report on Visit of South American Republics, 1945], Archivo Neutra, caja 1429, expediente 8.

7 Ibidem, p. 7.
} 
Durante las décadas cincuenta y sesenta varias agrupaciones y universidades latinoamericanas recibieron a Neutra. Viajó a Perú (Lima), Venezuela (Caracas), Guatemala (Antigua), Colombia (Barranquilla), Cuba (La Habana), Argentina (Buenos Aires) y México impartiendo conferencias en salones abarrotados de estudiantes.

A través de su presencia en la región y también de las publicaciones de su obra en revistas gremiales Neutra se convirtió en una figura de suma importancia para los arquitectos latinoamericanos sobre todo hacia el medio siglo. Para dimensionar esto vale la pena señalar que simplemente en Brasil, Segawa (1998: 149) identificó 137 artículos sobre su obra; en México tuvo una mayor presencia en la prensa especializada que Le Corbusier, Wright o Mies van der Rohe e, inclusive, su obra apareció con mas frecuencia que la de Luis Barragan y sus diseños fueron publicados en Arquitectura México, Arquitectura y Decoración, El Arquitecto y en Espacios, incluyendo un número monográfico con motivo de su fallecimiento en 1970 en Arquitectura/México. Una revisión superficial muestra que su obra fue publicada en Argentina en las revistas Arquitectura, Canon, Nuestra arquitectura y Sur. En Perú publicó en Espacio, El Arquitecto Peruano y en el Educador Peruano, en Venezuela aparecieron reseñas de su trabajo en El Farol. Adicionalmente el mismo Neutra promovió la publicación de tres de sus libros en la región incluyendo la traducción de Survival through Design (editado por Fondo de Cultural Económica en 1957 con el título Planificar para sobrevivir), Realismo Biológico (publicado en Argentina en 1958) y la edición bilingüe portugués-inglés Arquitetura social em paises de clima quente /Architecture of Social Concern in Regions of Mild Climate en São Paulo en 1948.

Se observa que no sólo dejó huella Neutra en América Latina, sino que también sus experiencias en la región dejaron huella en él, sobretodo, el proceso de diseño de escuelas, clínicas y hospitales en Puerto Rico donde pudo experimentar, reflexionar y profundizar en el tema de proyectos sociales, además de seguir explorando las posibilidades de diseño en climas templados. Sin duda, sus experiencias en América Latina enriquecieron sus escritos teóricos y su obra a su regreso a California (Ettinger, 2018). Resalta el tiempo en Puerto Rico, no por lo que se construyó, sino por los planteamientos de diseño y por la difusión que tuvieron en la región. Al respecto, Brett Tippey (2016) ha referido a su trabajo en América Latina como trabajo de campo y Puerto Rico como laboratorio para la experimentación de muchas de sus ideas. El mismo Neutra, probablemente en reconocimiento de la importancia de este episodio en su carrera, escribió en 1962 "El Sur abierto es lugar de prueba para Norte cerrado." (Neutra, [1962] 2009: 215).

\section{El ser biológico y el diseño para los trópicos.}

Desde 1954 Neutra, en un Survival through Design, texto que se ha considerado inaugural para la disciplina de diseño ambiental, dejó en claro su visión del ser humano como centro de todo esfuerzo del diseño. En este texto privilegió la idea del ser biológico, el orgánico, abogando por la aplicación en el diseño de los conocimientos que se generaban desde las neurociencias. Partió de una concepción del ser humano en relación con un sistema nervioso que oscilaba entre dos estados - uno inhibitorio y otro de excitación- o bien quedaba suspendido entre ellos en un estado de descanso (Neutra, 1954:214). El rol del arquitecto radicaban en manipular los estímulos y, por ende, tenía que ser experto en el funcionamiento del organismo humano (Neutra, 1954: 230). Debía aprovechar los avances en las neurociencias para comprender los efectos de los colores, las cualidades auditivas y las texturas sobre los humanos para poder aplicar este conocimiento efectivamente en el diseño. Los ensayos contenidos en Planificar para Sobrevivir ilustran su interés en estudios científicos de la percepción, en comprender el rol que jugaban los sentidos, más allá de la vista.

Sus reflexiones se ampliaron a incluir la percepción de la forma y los juicios estéticos sobre la belleza en 1962 con la publicación del libro Life and Shape en que desarrolló en diversos ensayos que reflejan la consolidación de sus ideas sobre arquitectura y su filosofía de realismo biológico. Propuso comprender la percepción de la arquitectura desde las funciones neurológicas; inclusive aboga por comprender a la forma y la percepción de la belleza en términos de funciones cerebrales (Neutra, [1962] 2009: 321).

Estas observaciones, que reaparecieron en textos y discursos, se vinculan con la inquietud de Neutra por entender a la arquitectura desde la 
perspectiva neurológica (Mallgrave, 2011: 102). En 1952, durante su visita a México, había insistido en una visión de la arquitectura desde el ser humano en una suerte de síntesis de la idea de realismo biológico: "la arquitectura se basa en el más actual y moderno conocimiento de los seres humanos... en su fisiología." Pero, aclaró que al hablar de fisiología, no solo ser refería al cuerpo sino "a la totalidad de cuerpo y mente." "En otro texto, recomendó prestar particular atención a "humedad, corrientes de aire, pérdida de calor, estimulación táctil, la gravedad y la resistencia del piso y otras respuestas musculares-esqueletales." (Mallgrave, 2011:106).

En la propuesta de Neutra el cliente figuraba de manera importante. Sobre el tema dejó varios textos inéditos en que enfatizaba la necesidad de la empatía por parte del arquitecto en el trato (Lavin, 2005: 32-35). Pero, al final, en el discurso de Neutra cobraba mayor importancia el usuario último de los espacios: el habitante, el niño, el paciente, el estudiante. Al tratar el tema del usuario, Neutra imaginaba su experiencia del espacio: el paciente en su cama o el niño en su salón.

En relación con la arquitectura escolar escribió mucho; una preocupación suya era la artificialidad de los ambientes escolares tradicionales y la institucionalización de la educación que se alejaba de la escala humana (Neutra 1944: 71) que podrían llevar a la "deprivación sensorial" del niño (Neutra, 2009: 327). En 1944 Neutra explicó sus ideas acerca del salón de clases de la siguiente manera:

"La estructura física de la escuela debe ampliar la tendencia a enfatizar y premiar la cooperación en lugar de la competencia. Los niños que entran a un salón hoy en día no se quedan sentados quietos, en una suerte de aislamiento paralelo o susurrar furtivamente a sus vecinos en sus pupitres atornillado al piso mientras supuestamente escuchan un sermón que resuena desde el pizarrón [...] su interés, su estimulación, su éxito será en el trabajo en equipo, en el ayudar en lugar de sobresalir. Una actividad muscular y sensorial coordinada requerirá de una agrupación flexible de los humanos y de sus muebles, para ajustar el ambiente educativo a los esfuerzos concertados varios y frecuentes.
¡Más espacio, más luz difusa, luz donde se requiere de más lados, menos colchones de aire caliente alrededor de los entrenados y menos sistemas de calefacción con contaminación del aire en aras de la economía!

¡Menos sitios encerrados y fijos, y más extensión hacia el exterior!

Ayudas acústicas hacia el silencio a través del aislamiento y una controlada reverberación hacia una articulación distinta de la oferta de sonidos - que serán definidos, no difuminados mientras pasan a las mentes.

Ayudas visuales no solo para la presentación de un tema en particular, pero para el desarrollo mental general de los niños a través de la claridad, la simplicidad y la sensibilidad en el diseño, aplicado al edificio en sí, a sus espacios, detalles de iluminación y esquemas de color.

¡El arquitecto hasta debe tomar en consideración el bien conocido olor agrio! Las exhalaciones rancias no deben convertirse en anti-estímulo perpetuo. Los materiales de las superficies que tienen la tendencia de absorber y acumularlos y seguirlos propagando deben evitarse." (Neutra, 1944: 71)

Esta larga cita ilustra la importancia de los sentidos en el diseño; la vista, el olfato, el tacto, y el oído están presentes en sus reflexiones sobre el espacio escolar que se derivan la lectura de textos de Darrell Harmon, quien había realizado estudios sobre la iluminación de los salones de clase. Harmon argumentaba que hacía daño a los niños por las postura que adoptaban que existiera una sola fuente de luz lateral; propuso ventanas altas y nuevos acomodos de mobiliario escolar para optimizar la visual de los estudiantes (Ogata, 2008: 569-70). Adicionalmente a los cambios en mobiliario, evidente en la cita anterior de Neutra, para las escuelas de Puerto Rico -que tenían dos fuentes de luz- procuró el reflejo de luz desde el plafón.

Prestó especial atención a la experiencia espacial en relación con el proceso de aprendizaje de los niños, lo que le sirvió para fundamentar sus novedosas propuestas en espacios escolares. Desde que realizó su trabajo utópico Rush City a principios de los años veinte, Neutra traía importantes ideas de innovación en arquitectura

\footnotetext{
${ }^{8}$ [Address by Richard J. Neutra FAIA, To an audience of architects, students and the public at the Auditorium, Social Security Building. Mexico City, October 4, 1951], Archivo Neutra, caja 217, expediente 10.
} 
escolar. En este trabajo presentó el diseño de la escuela en forma de un anillo con espacios verdes (campos deportivos) al centro y hacia el exterior. Promovía no solo un contacto directo entre el salón de clases al interior y la naturaleza, sin también cualidades ambientales que fomentarían la comodidad de los estudiantes. Las ideas presentes en este proyecto de Ringplan School se realizaron de una manera contundente en la Escuela de la Avenida Corona en Bell, California en 1935. Se trataba de una ampliación de una escuela existente que replanteó el espacio de los salones con continuidad entre espacio interior y exterior con salones con tres muros sólidos y un cuarto muro de puerta corrediza de vidrio que permitía extender el espacio del salón hacia un espacio ajardinado delimitado por vegetación. La idea era atender a los niños, inquietos por naturaleza, en un espacio que abandonaba de la rigidez típica de la escuela primaria tradicional a favor de espacios más lúdicos y libres. Estas ideas se implementaron en otros proyectos escolares que realizó el arquitecto, de manera notable en los proyectos que realizó para Puerto Rico entre 1944 y 1945.

Figura 1. Diagrama de estudio de asoleamiento y ventilación para el diseño de salones de clase.

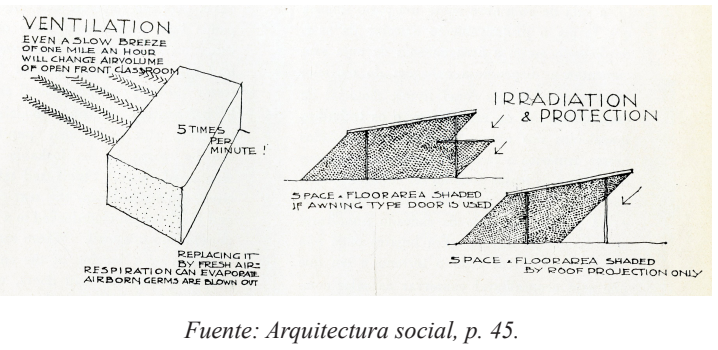

Figura 2. Solución de estructura con ventilación bajo el plafón para implementación en Puerto Rico.

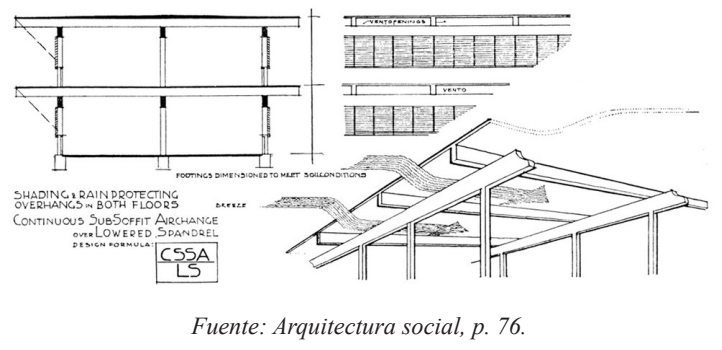

La traducción de estos conceptos en el diseño de proyectos específicos para clima templado tomó distintas formas. Para lograr confort térmico en los diseños para Puerto Rico ideó una estructura donde los marcos de acero quedaban separados del lecho inferior del plafón para permitir la circulación de aire; así se resolvía en una misma estructura el problema constructivo con elementos prefabricados y de fácil montaje y las condiciones de ventilación y temperatura deseables en el sitio. (Ver Figuras 1 y 2.) Aunque Neutra presentó varios esquemas, recomendó que las vigas de la estructura prefabricada se colocaran en el mismo sentido que el flujo de aire, es decir, perpendiculares al muro que envolvía el salón. Mencionó las ventajas del incremento de ventilación en su descripción del espacio: "Puertas levadizas permiten que las brisas agradables y constantes recorran el húmedo salón tres o cuatro veces por minuto y con esto retiren las bacterias transportadas por el aire. Ya no gotea el sudor, sino que se seca agradablemente, enfriando la piel" (Neutra, 1948: 50). Las puertas levadizas tenían la doble función de proveer sombra y de fomentar la circulación de aire en el lecho inferior de la cubierta. Acerca del diseño, escribió:

"La intención es contar con un denso seto de arbustos, posiblemente de hibisco que separe el edifico escolar [...] del tráfico exterior y segregue los patios abiertos de cada salón; estos serán utilizados para el estudio, la construcción de modelos o maquetas y la colocación flexible de equipo portátil." (Neutra, 1948: 50).

En todo caso, a partir de estas inquietudes, tuvo una particular sensibilidad en el diseño a los efectos de clima, de la iluminación y de la ventilación sobre los niños en sus salones de clase, los enfermos en camas hospitalarias y los habitantes de vivienda social, y más adelante, sobre oficinistas, llevando a buscar una luz difuminada con la implementación de persianas en el edificio del archivo de Los Ángeles que realizó con Robert Alexander entre 1961 y 1962.

El tema de la sensibilidad a la percepción sensorial apareció de nuevo en sus reflexiones generales sobre el diseño en climas tropicales:

"He intentado mostrar que el arquitecto siempre se enfrenta a un cliente multi-sensorial. El registro sensorial superficial de la temperatura se entreteje intimamente con otra información táctil cutánea de brisas refrescantes, de aire moviéndose sobre las antenas de los bellos en cada poro de nuestra piel y con una multiplicidad de sentidos interiores que son causados 
por respuestas fisiológicas a la humedad, carga eléctrica y modificaciones químicas del aire."

\section{El ser cultural y la introducción de la arquitectura moderna.}

El cometido social de la arquitectura fue pregonado por Neutra a lo largo de su carrera; en discursos en América Latina instigaba a los jóvenes arquitectos a servir a sus comunidades. Por ejemplo, en México insistía en que no había que servir solo al "comercio de lujo de la avenida Juárez" sino a las necesidades del pueblo. ${ }^{10}$ Aunque es mejor conocido por su arquitectura residencial, Neutra había realizado cuatro desarrollos de vivienda social a principios de los años cuarenta en Estados Unidos - tres en California (Pueblo del Río Housing, Hacienda Village Housing, Channel Heights) y una en Texas (Avion Village 1941) (Lamprecht, 2000: 160, 163, 169, 172-5). Esta experiencia le había proporcionado la oportunidad de observar detalladamente los ajustes en la vida familiar y comunitaria que implicaba el cambio en el tipo de habitación.

Neutra reconocía desde luego, que el ser humano, además de ser ente biológico era ente social; al respecto escribió "los organismos son fenómeno grupal y los seres humanos pertenecen a sociedades" (Neutra, 1954: 231). Esta reflexión surgió precisamente en relación con la idea de cambiar los hábitos de quienes, habiendo vivido en espacios tradicionales, serían cambiados a conjuntos modernos. Prosiguió con la reflexión: "en alterar una tradición o sustituirla por algo más, se debe tener en mente que nuevos hábitos o fijaciones no pueden crearse en el vacío, sino que se sedimentan a través del dominio de la novedad sobre los hábitos establecidos." (Neutra, 1952: 231).

Los proyectos de arquitectura social que fueron centrales al discurso de Neutra para América Latina implicaban precisamente la alteración de algunas costumbres y la adaptación de una nueva arquitectura moderna a las situaciones locales, y no solo en relación con factores ambientales. En el libro Arquitetura social se incluyeron proyectos de escuelas, centros comunitarios, clínicas y hospitales además de vivienda con la idea de que pudieran servir de modelos para implementación en otros países latinoamericanos (Neutra, 1948). En los primeros casos los proyectos referían los ejercicios en Puerto Rico, mientras en el rubro de vivienda social Neutra presentó, además de un ensayo con consideraciones generales, el proyecto de Channel Heights, un conjunto de 222 unidades multifamiliares para albergar las familias de 600 trabajadores del astillero de San Pedro en un conjunto de baja densidad. El mismo Neutra consideró el último proyecto particularmente relevante como ejemplo a seguir en la solución de problemas de vivienda en América Latina, así su inclusión en el libro.

Las propuestas de Neutra iban más allá de consideraciones materiales o de dispositivos climáticos, para incluir aspectos culturales como el uso del espacio. Al plantear el caso de las regiones de clima templado, en particular América Latina, entendió la necesidad de observar las prácticas locales. Por eso, al igual que para el caso ya mencionado de las escuelas, en los centros comunitarios y en la vivienda colectiva buscó incluir elementos como patios y porches. Para la vivienda, no solo se trataba de espacios abiertos para uso de la comunidad, sino como parte misma de la casa: "en un clima templado no es difícil proveer al usuario de un refugio pequeño, y el tamaño puede ser pequeño, y el costo puede ser bajo, porque, concebida apropiadamente, el exterior aquí siempre puede ser un 'espacio auxiliar' natural; el aire libre aquí más que en ningún otro lado, complementa el espacio vital" (Neutra, 1948: 194).

En otra referencia que nos remite al tema de diferencias culturales en la vivienda, Neutra notó que: "Generalmente [...] en los países tropicales hay una desatención nativa hacia límites marcados entre interior y exterior y este limite se define principalmente por el borde exterior del techo. En muchos de ellos la idea de privacidad es también menos marcada que entre nosotros, apenas es visual, y de menor preocupación que el flujo de aire. El calor húmedo produce una indiferencia extenuante hacia la privacidad hasta en europeos cuando se trasladan a los trópicos, y su pudor se reduce marcadamente bajo el impacto de la incomodidad..." 11

\footnotetext{
9 [Housing in Mild Climates], Archivo Neutra, caja 161, expediente 8.

${ }^{10}$ [Address by Richard J. Neutra FAIA, To an audience of architects, students and the public at the Auditorium, Social Security Building. Mexico, City. October 4, 1951] Archivo Neutr.a, caja 217, expediente 10.

${ }^{11}$ Ibidem.
} 
Esta cita muestra el reconocimiento de la estrecha relación entre clima, cultura y casa; la referencia al pudor y las ideas de privacidad implica no solo una reflexión sobre los usos al interior de la casa sino también de los efectos que podía tener la sustitución de la casa vernácula por una casa moderna. Valerie Fraser - considerando las propuestas de Neutra sobre la difusión de la tecnología y del consumo que permitiría un mercado de materiales prefabricados en aras de la reducción de costos de construcciónllegó a la conclusión de que Neutra era insensible a la cultura local. Escribió que había lanzado una guerra contra "el atraso" con "total desinterés por cualquier cultura u organización social existente entre aquellos cuyas vidas pretendía mejorar y con un propósito moral muy cercano al de los misioneros del siglo XVI" (Fraser, 2000: 169).

Aunque una lectura superficial de Arquitetura Social puede dar la impresión de que Neutra favorecía la imposición de la modernidad sobre los grupos tradicionales, se encuentra en su discurso mayor riqueza de reflexión y cierta ambigüedad que oscilaba entre la necesidad de educar a la población a través de la imposición de una nueva arquitectura -sobre todo para el caso de la vivienda- y la adecuación de los proyectos a las costumbres locales hace patente su sensibilidad hacia lo autóctono.

La conciliación entre el respeto por las culturas locales y la convicción de que la racionalidad de la arquitectura moderna representaba la solución a muchos de los problemas que se observaban en América Latina resultó problemático para Neutra. Sin embargo, implementó soluciones tendientes a lograr esta conciliación.

Figura 3. Centro comunitario para Puerto Rico organizado en torno a espacios abiertos.

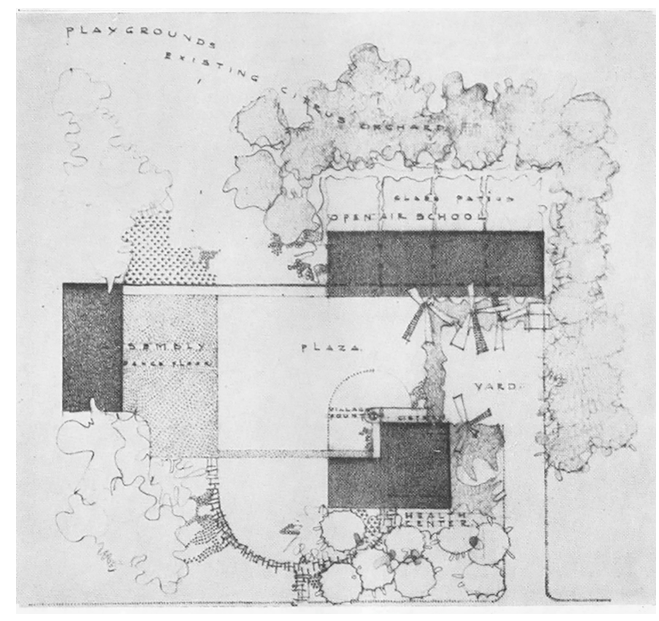

Fuente: Arquitectura social, p. 61
Figura 4. Centro rural de salud con patio para actividades de la comunidad.

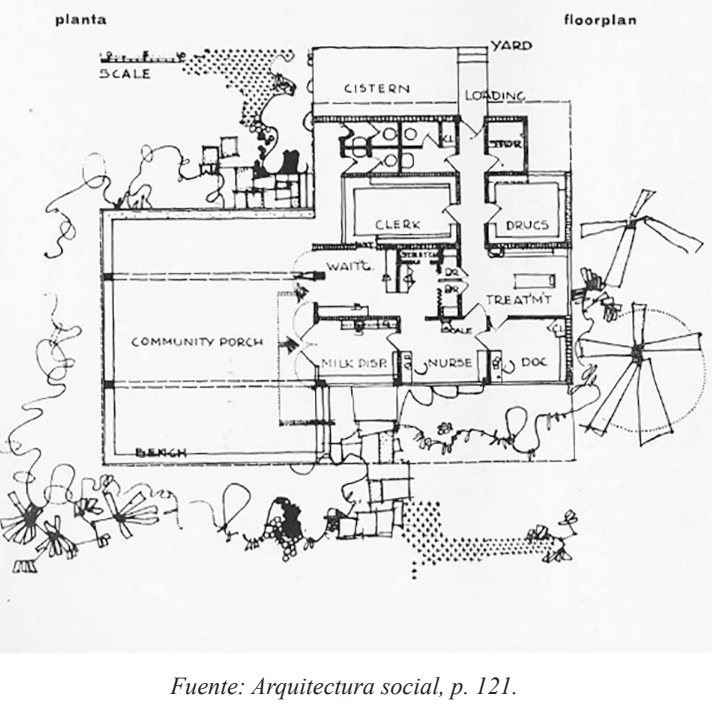

Por ejemplo, en el diseño de los centros comunitarios para Puerto Rico que reunían la escuela, la clínica rural, un dispensario de leche y una cocina comunitario en torno a una plaza central Neutra enfatizó la necesidad de atraer a la población con visitas de seguimiento. (Ver Figura 3.) Notó que uno de los problemas principales para el éxito de la introducción de estos equipamientos tenía que ver con su recepción por parte de la población local. En el diseño incluyó espacios de convivencia y privilegió el diseño de espacios que se adecuaban a las usanzas locales. Así se lograría el acogimiento del sitio por parte de la sociedad. Consideró primordial que los habitantes locales fueran instrumentos para "difundir [su] nueva fe [en la medicina moderna] entre las personas de sus vecindarios" (Neutra, 1948: 123). Para lograr este fin, incorporó amplios porches con bancas y plazas sombreadas "donde los 'jíbaros' o campesinos pobres de la montaña, pueden disfrutar su propia vida social, jugar dominó en la tarde, tocar la guitarra o bailar en el amplio porche" (Architectural Forum, 1945: 125). (Ver Figura 4.) En otro gesto atento a la población local, incluyó en algunos centros de salud, patios para juegos donde los niños podían esperar a sus mamás (Neutra, 1948:142). (Ver Figura 4.) 
Figura 5. Centro de Salud con área de juego para niños.

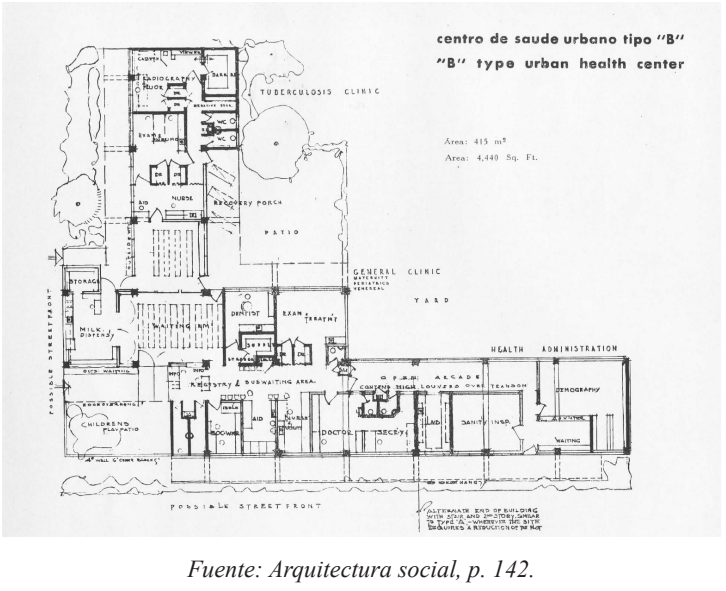

En Arquitetura social Neutra reconoció la complejidad inherente al proceso de introducción de vivienda moderna a pobladores rurales. La propuesta de vivienda nueva era una propuesta educativa que Neutra describió como la tarea de "trasplantar y cambiar de maceta de una planta, pero en masa donde no se puede esperar que las cosas se resuelvan solas. Tiene que ser una aventura de entrenamiento supervisado con cuidado; de otra manera, las personas no enraizarán [...]" (Neutra 1948;192-3) En esta cita no hay referencia a los deseos u opiniones de los habitantes, tal vez de ahí la crítica ya citada de Valery Fraser; defendió esta posición a través de una analogía entre el habitante de los arrabales y el alcohólico: "No son consumidores con elección; son víctimas de las únicas viviendas disponibles que tienen que consumir desde su infancia. No sirve de nada hablar de moral si a un alcohólico no le gustan los refrescos y la leche. Se requiere de un cuidadoso y diligente entrenamiento de su voluntad, iniciativa, gusto y su complexión general de comportamiento..." (Neutra, 1948:200).

Esto sin duda despierta cuestionamientos desde la perspectiva actual, pero en su momento era un punto de vista aceptado; la modernidad arquitectónica aún se veía como la solución no solo universal por su racionalidad, sino eterna (Eisenman [1984] 1996), el último estilo. Neutra, sin embargo, era sensible a la necesidad de implementar los cambios con atención hacia las prácticas espaciales locales. En el libro de Arquitetura social propuso la introducción de una nueva vi- vienda de manera paulatina. Sugirió al principio la construcción de unidades de baños y áreas de lavado que serían compartidas entre varias casas, replicando algunas costumbres locales de espacios compartidos y de viviendas conformadas por diversas estructuras dispersas en un gran solar. Advirtió que el contar con áreas comunes para estas actividades no iba en contra de la tradición local (Neutra, 1948:191). En un sentido similar, propuso la organización espacial en torno a una fuente central, para tener agua potable a una distancia razonable para cada vivienda.

Neutra también consideró que era importante evitar imponer una planeación rígida, sino que debía de dejar abierta la posibilidad para futuras generaciones de implementar "soluciones mejores y más avanzadas cuando llegara la oportunidad." A pesar de las buenas intenciones y el reconocimiento del valor de la casa tradicional, el lenguaje utilizada implica la valoración de lo tradicional como de alguna manera atrasada, y la casa moderna capaz de ofrecer mejores condiciones de vida. ${ }^{12}$

Sin duda, aunque Neutra era sensible a las condiciones y cultura de los países americanos, tenía un compromiso ineludible con los principios del movimiento moderno y creía en el poder transformador de la arquitectura y de la tecnología. Para él, al igual que para sus contemporáneos el rol del arquitecto iba más allá del diseño de espacios para incluir la educación; era menester del arquitecto educar y civilizar al habitante de los trópicos, siendo la arquitectura una herramienta. A pesar de esto, las consideraciones para el diseño giraban en torno al reconocimiento del habitante en términos de su cultura no de un ser abstracto universal.

\section{Consideraciones finales.}

A través de estas líneas se ha querido enriquecer la perspectiva historiográfica sobre una de las principales figuras del movimiento moderno al traer a la luz, por una parte, la importancia de sus experiencias en América Latina y por otra sus ideas sobre el ser humano. Como prolífico escritor, Neutra dejó numerosos ensayos que permiten comprender la manera en que su visión del diseño centrado en el ser humano rescata una

\footnotetext{
${ }^{12}$ Ibidem, p. 194.
} 
perspectiva alejada de las abstracciones universales que en ocasiones sirvieron de fundamento al proyecto moderno en arquitectura. Su ser biológico presagió el ser fenomenológico que aparecería en la literatura algunas décadas después. Los textos en los que describe detalladamente la experiencia sensorial del espacio prefiguraron de cierta manera las formulaciones recientes en la disciplina. Aunque desde luego desde raíces diferentes -Neutra desde las neurociencias y Pallasmaa (2005) desde la fenomenología- se observan coincidencias en la inquietud por la percepción de la arquitectura más allá de la vista. Para ambos, la experiencia de la arquitectura puede redundar en sensaciones de bienestar integral, por ende, las consideraciones de estas sensaciones deben ser central en el proceso de diseño.

Tal vez en la formulación del ser cultural se encuentra con menor solidez en los ensayos de Neutra. El conflicto entre la propuesta absoluta de la modernidad arquitectónica en su racionalidad y la aceptación de las diferencias culturales y la atención al ser social quedó irresuelto en muchos de ellos.

En todo caso, a través de esta revisión que reconoce que, además de sus aportaciones en la depuración de los lenguajes modernos, en la gestación de una modernidad californiana y en soluciones técnicas para la construcción con materiales industrializados, Neutra fue un importante precursor de inquietudes contemporáneas en relación con el ser humano. C

\section{Referencias bibliográficas.}

Ábalos, I. (2000). La buena vida. Visita guiada a las casas de la modernidad. Barcelona, Gustavo Gili.

Architectural Forum (1945), "Schools Are Planned by the Hundreds in Puerto Rico's Campaign against Illiteracy", en Architectural Forum, marzo 1945, pp. 121-130.

Benevolo, L. (1977). History of Modern Architecture. Cambridge, MIT Press.

Carranza, L. y Luiz Lara, F. (2014). Modern Architecture in Latin America. Art, Technology, and Utopia. Austin, The University of Texas Press.

Critelli de Campos, F. (2015). Richard Neutra e o Brasil. Tesis de maestría, Faculdade de Arquitetura e Urbanismo, Universidade Presbiteriana Mackenzie, São Paulo.
Eisenman, P. [1984] 1996. The End of the Classical: the End of the Beginning, the End of the End, en Nesbitt, Kate (ed.), Theorizing a New Agenda for Architecture. An Anthology of Architectural Theory. 1965-1995. New York, Princeton Architectural Press.

Espegel, C. (2007). Heroinas del Espacio. Mujeres Arquitectos en el Movimientos Moderno. Buenos Aires, Nobuko.

Frampton, K. ([1980] 1992). Modern Architecture. A Critical History, New York, Thames and Hudson.

Fraser, V. (2000). Building the New World. Studies in the Modern Architecture of Latin America 19301960. London \& New York, Verso Books.

Hines, T. S. (1982). Richard Neutra and the Search for Modern Architecture. A Biography and History. New York \& Oxford, Oxford University Press.

Hitchcock, H. R. (1955). Latin American Architecture since 1945. New York, Museum of Modern Art.

Lamprecht, B. (2000). Neutra. Complete Works. Cologne, Taschen.

Lavin, S. (2005). Form Follows Libido. Architecture and Richard Neutra in a Psychoanalytic Culture. Cambridge, MIT Press.

Leatherbarrow, D. (2000). Uncommon Ground. Architecture, Technology, and Topography, Cambridge and London, MIT Press.

Lira, J. (2010). "From Mild Climate's Architecture to 'Third World' Planning: Richard Neutra in Latin America," ponencia presentada en 14th International Planning History Society Conference. Recuperado: http://www.iphs2010.com/ abs/ID457.pdf

Mallgrave, H. (2011). The Architect's Brain. Neuroscience, Creativity, and Architecture. Chichester, Wiley-Blackwell.

Neutra, R. (1944). "Classrooms and Living Rooms" en Zucker, Paul (ed.), New Architecture and City Planning. A Symposium. New York, Philosophical Library, pp. 57-72.

Neutra, R. ([1962] 2009), Life and Shape, Los Angeles, Atara Press.

Neutra, R. (1948). Arquitetura social em paises de clima quente/Architecture of Social Concern in Regions of Mild Climate. São Paulo, Gerth Todtmann.

Neutra, R. (1954). Survival through Design, London, Oxford \& Los Angeles, Oxford University Press. 
Ogata, A. (2008). "Building for Learning in Postward Elementary Schools". En: Journal of the Society of Architectural Historians, Vol. 67, núm 4, pp. 562-591.

Pallasmaa, J. (2005). The Eyes of the Skin. Architecture and the Senses. London: Wiley.

Segawa, Hugo, Arquiteturas no Brasil. 19001990, Sao Paulo, Editora da Universidade de Sao Paulo, 1998.

Tippey, B. (2016). "Richard Neutra's Search for the Southland: California, Latin America and Spain," en Architectural History, 59, pp. 311-352 Treib, Marc, Landscapes of Modern Architecture. Wright, Mies, Neutra, Aalto, Barragán, New Haven, Yale University Press, 2017. 